\title{
Appendage to: Multi-part balanced incomplete-block designs
}

\author{
R. A. Bailey ${ }^{1,2}$ (D) Peter J. Cameron ${ }^{1,2}$
}

Received: 12 September 2019 / Revised: 12 September 2019 / Published online: 29 October 2019

(c) The Author(s) 2019

\section{Appendage to: Statistical Papers https://doi.org/10.1007/s00362-018-01071-x}

Soon after the publication of Bailey and Cameron (2019), we became aware of the paper by Martin (1998). This paper uses the name 'mixed block designs' for the special case of our designs with exactly two parts, but slightly generalized to allow $\lambda_{i i}=0$ for either $i=1$ or $i=2$. It was contemporaneous with Mukerjee (1998), but independent of that and of Sitter (1993). Furthermore, relaxing the conditions that $k_{1}$ and $k_{2}$ are both constant across blocks to the condition that the total $k_{1}+k_{2}$ is constant across blocks gives the 'balanced bipartite block designs' introduced by Kageyama and Sinha (1988) and Sinha and Kageyama (1990).

The first four constructions in Bailey and Cameron (2019, Sect. 2) are given in Martin (1998, Sect. 1). The lower bound in our Eq. (4) is given in Theorem 2.2 of Martin (1998).

Open Access This article is distributed under the terms of the Creative Commons Attribution 4.0 International License (http://creativecommons.org/licenses/by/4.0/), which permits unrestricted use, distribution, and reproduction in any medium, provided you give appropriate credit to the original author(s) and the source, provide a link to the Creative Commons license, and indicate if changes were made.

The original article can be found online at https://doi.org/10.1007/s00362-018-01071-x.

$\bowtie \quad$ R. A. Bailey

rab24@st-andrews.ac.uk

1 School of Mathematics and Statistics, University of St Andrews, North Haugh, St Andrews, Fife KY16 9SS, UK

2 School of Mathematical Sciences, Queen Mary University of London, Mile End Road, London E1 4NS, UK 


\section{References}

Bailey RA, Cameron PJ (2019) Stat Pap 60:55-76

Kageyama S, Sinha K (1988) Some constructions of balanced bipartite block designs. Util Math 33:137-162 Martin WJ (1998) Mixed block designs. J Comb Des 6:151-163

Mukerjee R (1998) On balanced orthogonal multi-arrays: existence, construction and application to design of experiments. J Stat Plan Inference 73:149-162

Sinha K, Kageyama S (1990) Further constructions of balanced bipartite block designs. Util Math 38:155160

Sitter RR (1993) Balanced repeated replications based on orthogonal multi-arrays. Biometrika 80:211-221

Publisher's Note Springer Nature remains neutral with regard to jurisdictional claims in published maps and institutional affiliations. 